\title{
Dampak Perubahan Pola Konsumsi Pangan Lokal Ubi dan Sagu Menjadi Pangan Beras di Kampung Makimi, Distrik Makimi, Kabupaten Nabire, Provinsi Papua
}

\author{
ROSDIANA BARANSANO, I WAYAN WINDIA, I DEWA PUTU OKA SUARDI
}

\author{
Program Studi Agribisnis, Fakultas Pertanian,Universitas Udayana \\ Jl. PB. Sudirman Denpasar 80323,Bali \\ e- mail: rosdianabaransano@gmail.com \\ Wayanwindia@ymail.com
}

\author{
Abstract \\ The Impact of Changes in Local Food Consumption \\ of Sweet Potato and Sago into Rice Food, \\ in Kampung Makimi, Makimi District, \\ Nabire Regency, Papua Province
}

The impact of rice policy is a change in the pattern of local food consumption of the community. This study aims to determine the impact of changes in the pattern of consumption of sweet potato and sago local food into rice food consumption. The sampling method uses simple random sampling as many as 40 household headsfrom 402 populations, theanalysis method used in this study is qualitative descriptive. The results showedthe impact of changes in the pattern of consumption of local food of sweet potatoes and sago into rice consumption was a massive shift in public consumption resulted in a decrease in the level of preference for local sweet potato and sago food consumption. Most households prefer to consume rice food, because it tastes good and is easily accessible. This can be seen by the amount of rice consumption as much as $1,443.8 \mathrm{~kg} /$ year, while the amount of sweet potato consumption is $182.4 \mathrm{~kg} /$ year, and sago is $728 \mathrm{~kg} /$ year. The negative impact of government policies and programs on rice food availability has resulted in reduced production of local sweet potatoes and sago. So the price of sweet potatoes and sago became expensive. Changes in the pattern of consumption of local foods of sweet potatoes and sago into rice resulted in an increase of $18.75 \%$ in Diabetes Meliatus in Makimi Makimi Village. Suggestion that can be submitted as input is that necessary to process local food into value-added commodities that can attract households to consume local food. The government is expected to formulate regulations related to the food sovereignty program, especially local sweet potatoes and sago. Government policies for the assistance of raskin should be reduced by quota, and replaced by a food subsidies program based on local food. There needs to be a tithe regarding the diversification of consumption of nutritiousbalanced food, especially in utilizing local food potential.

Keywords: consumption, local food, rice

\section{Pendahuluan}

\subsection{Latar Belakang}

Kedaulatan pangan adalah konsep pemenuhan pangan melalui produksi lokal. Kedaulatan pangan merupakan konsep pemenuhan hak atas pangan yang berkualitas 
gizi baik dan sesuai secara budaya, di produksi dengan sistem pertanian yang berkelanjutan dan ramah lingkungan. Undang Undang RI No.18 tahun 2012 tentang pangan menyatakan bahwa pangan adalah segala sesuatu yang berasal dari sumber hayati produk pertanian, perkebunan, kehutanan, perikanan, peternakan, perairan, dan air, baik yang diolah maupun tidak diolah yang diperuntukkan sebagai makanan atau minuman bagi konsumsi manusia, termasuk bahan tambahan pangan, bahan baku pangan, dan bahan lainnya yang digunakan dalam proses-proses penyiapan pengolahan, dan pembuatan makanan atau minuman (Janes\&Rivale :2011).

Pangan lokal umbi-umbian dan sagu merupakan makanan pokok bagi masyarakat di Tanah Papua mencakup Provinsi Papua dan Papua Barat. Masyarakat di Tanah Papua kini mengalami proses perubahan termasuk dalam makanan pokoknya yang semula sagu, umbi-umbian perlahan-lahan tergantikan oleh beras yang notabene bukan makanan asli Papua. Konsumsi beras di Provinsi Papua dan Papua Barat rata-rata mencapai 132.000 ton per tahun. Besaran itu sekitar $74 \%$ merupakan beras yang di datangkan dari luar daerah (BPS Provinsi Papua), khususnya pada rumah tangga di Kampung Makimi, Distrik Makimi, Kabupaten Nabire. Rumah tangga di Kampung Makimi, Distrik Makimi, mengalami proses perubahan termasuk dalam makanan pokoknya yang semula sagu, umbi-umbian perlahan-lahan tergantikan oleh beras yang notabene bukan makanan asli Papua.

Perubahan pola konsumsi rumah tangga yang tadinya mengkonsumsi pangan lokal beralih mengkonsumsi beras merupakan salah satu dampak dari program pemerintah yang berprioritas akan ketersediaan komoditas beras pada tahun 2012 hingga saat ini. Perubahan itu yang kemudian berdampak pada menurunya produksi pangan lokal, dan adanya kebijakan atau program yang justru mengeliminasi tujuan penganekaragaman seperti, pembagian beras untuk masyarakat miskin (raskin). Dampak positif akan ketersediaan pangan beras merupakan hal yang baik, namun adanya dampak negatif bagi masyarakat setempat yang mengakibatkan perubahan pola konsumsi rumah tangga di Kampung Makimi dari mengkonsumsi sagu dan ubi pada konsumsi beras.

\subsection{Rumusan Masalah}

Berdasarkan uraian di atas permasalahan yang dapat di ambil adalah bagaimana dampak perubahan pola konsumsi pangan lokal ubi dan sagu menjadi pangan beras di Kampung Makimi, Distrik Makimi, Kabupaten Nabire?

\subsection{Tujuan Penelitian}

Adapunt ujuan penelitian ini adalah, untuk mengetahui dampak perubahan pola konsumsi pangan lokal ubi dan sagu menjadi pangan beras di Kampung Makimi, Distrik Makimi, Kabupaten Nabire.

\section{Metode Penelitian}

\subsection{Lokasi dan Waktu Penelitian}

Penelitian ini dilaksanakandi Kampung Makimi, Distrik Makimi, Kabupaten Nabire, Provinsi Papua. Pelaksanaan penelitian dilakukan pada bulan September sampai dengan November 2017. Penentuan lokasi ini dilakukan secara sengaja karena Kampung Makimi merupakan salah satu kampung sentra ubi dan sagu yang secara langsung mengalami perubahan pola konsumsi pangan pokok lokal ubi dan sagu menjadi pangan beras. Berdasarkan sumber data Susenas Panel Provinsi Papua, tahun 
(2008-2010) mengindikasikan bahwa terdapat perubahan konsumsi pangan pokok dari sagu dan ubi menjadi lebih menyukai beras pada kelompok daerah yang berpotensi sagu dan ubi.

\subsection{Jenis dan sumber Data \\ 2.2.1 Jenis data}

Jenis data yang di gunakan dalam penelitian ini meliputi data kuantitatif dan data kualitatif. Data kuantitatif yaitu jenis data yang dapat dihitung berupa angka-angka seperti, jumlah konsumsi pangan beras, jumlah konsumsi pangan lokal ubi dan sagu. Harga pangan beras, harga pangan lokal ubi dan sagu. Data kualitatif, yaitu data yang tidak berupa angka-angka seperti, jenis pangan yang dikonsumsi. Tingkat kesukaan terhadap konsumsi pangan ubi, sagu dan beras. Ketersediaan konsumsi ubi, sagu dan beras.

\subsubsection{Sumber data}

Sumber data yang dikumpulkan dalam penelitian ini adalah data primer yaitu data yang meliputi identitas responden, jawaban responden atas pertanyaan wawancara. Data sekunder adalah data penunjang dari instansi-instansi atau lembaga terkait seperti: Dinas Pertanian dan Perkebunan Badan Penyuluhan dan Ketahanan Pangan, serta berbagai sumber seperti Badan Pusat Statistik (BPS), jurnal, dan lainnya.

\subsection{Metode Pengumpulan Data}

Metode pengumpulan data yang digunakan dalam penelitian adalah wawancara (interview) dan teknik pengumpulan data dengan mengadakan tanya jawab/wawancara langsung kepada responden dengan menggunakan daftar pertanyaan. Observasi yakni peneliti datang secara langsung ketempat penelitian untuk melihat/mengamati langsung.

\subsection{Populasi dan Sampel Penelitian}

Populasi dalam penelitian ini adalah rumah tangga Kampung Makimi, Distrik Makimi, Kabupaten Nabire yang berjumlah 402 KK. Penelitian ini penentuan responden dilakukan dengan cara teknik simple random sampling, yakni suatu teknik pengambilan yang memberikan kesempatan yang sama kepada populasi untuk dijadikan responden. Syarat untuk melakukan simple random sampling adalah anggota populasi tidak memiliki strata sehingga relatif homogen. Gay (1992) menyatakan bahwa untuk menentukan besaran responden dari populasi yang bersifat deskriptif minimum adalah $10 \%$ maka dalam penelitian ini responden ditetapkan sebesar $10 \%$ dari 402 populasi. Jumlah responden yang di tetapkan sebanyak 40 Kepala Keluarga (KK), karena dengan sampel tersebut dianggap presentatif mewakili populasi. Pengambilan sampel secara random pada penelitian ini dilakukan dengan cara undian.

\subsection{Analisis Data}

Analisis data yang di gunakan pada penelitian ini adalah deskriptif kualitatif. Sugiyono (2003) menyatakan bahwa metode penelitian deskriptif kualitatif bertujuan untuk menggambarkan apa-apa yang saat ini berlaku. Metode penelitian ini terdapat upaya mendeskripsikan, analisis, mencatat dan menginterprestasikan kondisi yang terjadi. Penelitian deskriptif bertujuan untuk memperoleh informasi yang ada dan melihat kaitan antara variabel-variabel. Penelitian ini tidak menggunakan hipotesa atau menguji hipotesa, tetapi hanya mendeskripsikan informasi apa adanya sesuai dengan 
variabel yang di teliti yang berhubungan dengan dampak perubahan pola konsumsi pangan lokal ubi dan sagu menjadi konsumsi beras di Kampung Makimi, Distrik Makimi, Kabupaten Nabire.

\section{Hasil dan Pembahasan}

\subsection{Tingkat Kesukaan Konsumsi Pangan Ubi, Sagu dan Beras Sebelum dan Setelah perkembangan Konsumsi Beras}

Tabel 1.

Tingkat Kesukaan Konsumsi Pangan Ubi, Sagu dan Beras

\begin{tabular}{lccc}
\hline \multirow{2}{*}{ Komoditi } & Kategori & \multicolumn{2}{c}{ Tingkat Kesukaan Konsumsi } \\
\cline { 3 - 4 } & Sebelum & $\begin{array}{c}\text { Sebelum } \\
\text { perkembangan } \\
\text { konsumsi beras } \\
\text { (tahun 2012) }\end{array}$ & $\begin{array}{c}\text { kerkembangan } \\
\text { konsumsi beras } \\
\text { (tahun 2016) }\end{array}$ \\
\hline \multirow{3}{*}{ Sagi } & Sedikit & - & $87,5 \%$ \\
& Cukup & $25 \%$ & $12,5 \%$ \\
\hline & Banyak & $75 \%$ & - \\
\hline \multirow{2}{*}{ Beras } & Total & $100 \%$ & $100 \%$ \\
& Sedikit & - & $65 \%$ \\
& Cukup & - & $10 \%$ \\
\hline & Banyak & $100 \%$ & - \\
\hline & Total & $100 \%$ & - \\
\hline & Sedikit & $27,5 \%$ & $100 \%$ \\
\hline
\end{tabular}

Sumber: Data Primer diolah, 2017.

Keterangan: (Sedikit < 0,3 kg/org/hari), (Cukup 0,3 kg/org/hari), (Banyak > 0,3 $\mathrm{kg} / \mathrm{org} / \mathrm{hari}$ ).

Tabel 1 dapat dilihat bahwa tingkat kesukaan konsumsi pangan lokal ubi setelah perkembangan konsumsi beras mengalami perubahan dari total 40 responden rumah tangga, terdapat $87,5 \%$ rumah tangga yang memilih tingkat kesukaan konsumsi ubi pada kategori sedikit. Perubahan ini terlihat pada tingkat kesukaan konsumsi pangan ubi yang $<0,3 \mathrm{~kg} /$ orang/hari. Tingkat kesukaan konsumsi pangan lokal sagu setelah perkembangan konsumsi pangan beras, sebanyak 65\% rumah tangga memilih tingkat kesukaan konsumsi pangan lokal sagu pada kategori sedikit. Perubahan ini juga terlihat pada tingkat kesukaan konsumsi pangan sagu yang kurang dari $0,3 \mathrm{~kg} / \mathrm{orang} / \mathrm{hari}$. Konsumsi pangan beras rumah tangga setelah adanya perkembangan konsumsi beras sebanyak 100\% rumah tangga memilih tingkat kesukaan konsumsi beras pada kategori banyak. Perubahan ini terlihat pada tingkat kesukaan konsumsi beras yang $>0,3$ $\mathrm{kg} /$ orang/hari.

Perubahan ini sesuai dengan hasil wawancara terhadap responden yang mengatkan lebih menyukai mengkonsumsi pangan beras karena rata-rata semua anggota keluarga rumah tangga lebih menyukai konsumsi beras/nasi. Responden mengatakan apabila dalam sehari menyediakan jenis makan seperti (ubi, sagu dan beras) kebanyakan dari anggota rumah tangga lebih dominan memilih mengkonsumsi nasi/beras dari pada ubi 
dan sagu. Perubahan tersebut menunjukan tingkat kesukaan konsumsi beras semakin banyak dibandingkan konsumsi pangan lokal ubi dan sagu. Perubahan ini sesuai dengan hasi penelitian yang menunjukan adanya perubahan tingkat kesukaan rumah tangga mengkonsumsi pangan beras dibandingkan pangan lokal ubi dan sagu, setelah adanya perkembangan konsumsi beras.

\subsection{Ketersediaan Konsumsi Pangan Ubi, Sagu, dan Beras Sebelum dan Setelah Perkembangan Konsumsi Beras}

Tabel 2.

Ketersediaan Konsumsi Pangan Ubi, Sagu dan Beras

\begin{tabular}{llcc}
\hline \multirow{2}{*}{ Komoditi } & Kategori & \multicolumn{2}{c}{ Ketersediaan Konsumsi Pangan } \\
\cline { 3 - 4 } & & $\begin{array}{c}\text { Sebelum } \\
\text { perkembangan } \\
\text { konsumsi beras } \\
\text { (tahun 2012) }\end{array}$ & $\begin{array}{c}\text { Setelah } \\
\text { perkembangan } \\
\text { konsumsi beras } \\
\text { (tahun 2016) }\end{array}$ \\
\hline \multirow{3}{*}{ Ubi } & Sedikit & - & $92,5 \%$ \\
& Cukup & $15 \%$ & $7,5 \%$ \\
\hline \multirow{3}{*}{ Sagu } & Banyak & $85 \%$ & - \\
& Total & $100 \%$ & $100 \%$ \\
\hline \multirow{3}{*}{ Beras } & Sedikit & - & $37,5 \%$ \\
& Cukup & - & $10 \%$ \\
\hline & Banyak & $100 \%$ & $100 \%$ \\
\hline & Total & $100 \%$ & - \\
\hline
\end{tabular}

Sumber: Data Primer diolah, 2017.

Keterangan: Sedikit $<0,3 \mathrm{~kg} / \mathrm{org} / \mathrm{hari}$, Cukup 0,3 kg/org/hari, Banyak

$>0,3 \mathrm{~kg} /$ org/hari.

Tabel 2 dapat dilihat bahwa ketersediaan konsumsi pangan lokal ubi setelah perkembangan beras mengalami perubahan, dari total 40 responden rumah tangga terdapat 97,5\% rumah tangga memilih ketersediaan konsumsi pangan ubi pada kategori sedikit. Perubahan ini terlihat pada ketersediaan konsumsi pangan ubi yang $<0,3$ $\mathrm{kg} /$ orang/hari. Perubahan ketersediaan konsumsi pangan sagu setelah perkembangan beras sebanyak 57,5\% rumah tangga memilih ketersediaan konsumsi pangan lokal sagu pada kategori sedikit. Perubahan terlihat pada ketersediaan konsumsi pangan sagu yang $<0,3 \mathrm{~kg} /$ orang/hari. Perubahan konsumsi pangan beras setelah adanya perkembangan konsumsi beras sebanyak 95\% rumah tangga memilih ketersediaan mengkonsumsi beras pada kategori banyak, hal ini terlihat pada ketersediaan konsumsi beras yang > $0,3 \mathrm{~kg} / \mathrm{orang} / \mathrm{hari}$.

Menurut responden hal ini terkait adanya subsidi (raskin) yang dilakukan pemerintah sehingga semakin muda dalam ketersediaan konsumsi pangan beras. Hasil penelitian dan pernyataan responden yang menunjukkan ketersediaan pangan beras yang semakin meningkat dibandingkan pangan lokal berdampak pada menurunya 
produksi dan produktivitas sumber pangan non beras. Rumah tangga mulai meninggalkan konsumsi pangan lokal, dan mengkonsumsi pangan beras yang lebih terjangkau.

\subsection{Persepsi terhadap Keterjangkauan Harga Pangan Ubi, Sagu, dan Beras Sebelum dan Setelah Perkembangan Konsumsi Beras}

Tabel 3.

Persepsi terhadap Keterjangkauan Harga Pangan Ubi, Sagu, dan Beras

\begin{tabular}{|c|c|c|c|}
\hline \multirow[b]{2}{*}{ Komoditi } & \multirow[b]{2}{*}{ Kategori } & \multicolumn{2}{|c|}{ Persepsi Keterjangkauan Harga } \\
\hline & & $\begin{array}{c}\text { Sebelum } \\
\text { perkembangan } \\
\text { konsumsi beras } \\
\text { (tahun 2012) }\end{array}$ & $\begin{array}{c}\text { Setelah } \\
\text { perkembangan } \\
\text { konsumsi beras } \\
\text { (tahun 2016) }\end{array}$ \\
\hline \multirow{4}{*}{ Ubi } & Murah & $100 \%$ & - \\
\hline & Cukup murah & - & $12,5 \%$ \\
\hline & Mahal & - & $87,5 \%$ \\
\hline & Total & $100 \%$ & $100 \%$ \\
\hline \multirow{4}{*}{ Sagu } & Murah & $100 \%$ & - \\
\hline & Cukup murah & - & $25 \%$ \\
\hline & Mahal & - & $75 \%$ \\
\hline & Total & $100 \%$ & $100 \%$ \\
\hline \multirow{4}{*}{ Beras } & Murah & - & $82,5 \%$ \\
\hline & Cukup murah & $5 \%$ & $17,5 \%$ \\
\hline & Mahal & $95 \%$ & - \\
\hline & Total & $100 \%$ & $100 \%$ \\
\hline
\end{tabular}

Sumber:Data Primer diolah,2017.

Keterangan: Murah < Rp 10.000/kg, Cukup murah Rp 10.000/kg, Mahal >

Rp.10.000/kg Murah Rp. <10.000/kg, Cukup murah Rp.10.000/kg, Mahal >

Rp. $10.000 / \mathrm{kg}$.

Tabel 3 dapat dilihat bahwa keterjangkauan harga pangan lokal ubi setelah perkembangan beras mengalami perubahan, dari total 40 responden rumah tangga, terdapat $87,5 \%$ rumah tangga memilih keterjangkauan harga ubi pada kategori mahal. Perubahan ini terlihat pada harga ubi yang mahal yaitu > Rp.10.000,00. Keterjangkauan harga pangan lokal sagu setelah perkembangan konsumsi beras mengalami perubahan, terdapat $75 \%$ rumah tangga memilih keterjangkauan harga sagu pada kategori mahal. Perubahan tersebut terlihat pada harga sagu yang mahal $>\mathrm{Rp}$. $10.000,00 / \mathrm{kg}$, karena produksinya semakin berkurang mengakibatkan harganya lebih mahal yaitu Rp 10.000,00/kg sampai Rp 20.000.00/kg. Keterjangkauan harga beras setelah perkembangan konsumsi beras juga mengalami perubahan, terdapat $82,5 \%$ rumah tangga memilih keterjangkauan harga beras pada kategori murah. Perubahan ini terlihat pada keterjangkauan harga beras yang murah $<$ Rp. 10.000,00/kg.

Berdasarkan hasil wawancara terhadap responden yang mengatakan keterjangkauan harga pangan beras semakin murah karena, adanya bantuan raskin dengan harga Rp. 1.700,00/kg. Harga beras dari segi produksi dengan harga pasaran Rp $10.000,00 / \mathrm{kg}$ sampai Rp. 13.000,00/kg. Perubahan keterjangkauan harga ini sejalan dengan pernyataan responden rumah tangga yang mengatakan bahwa adanya 
perkembangan pangan beras, melalui bantuan raskin yang disalurkan setiap bulan dengan harga yang murah. Raskin yang di salurkan mengakibatkan perkembangan konsumsi pangan beras mudah dijangkau oleh rumah tangga. Berbagai kebijakan dan program swasembada pangan beras yang di canangkan oleh Pemerintah Kabupaten Nabire, dengan maksud mempermudah akses masyarakat terhadap pangan dari segi produksi dan produktivitas beras yang mudah dijangkau untuk dikonsumsi.

Berdasarkan hasil penelitian tersebut apabila dibandingkan dengan sebelum perkembangan konsumsi beras harga ubi dan sagu masih sangat murah, sehingga lebih terjangkau untuk dikonsumsi. Harga yang masih terjangkau yaitu $\mathrm{Rp} 3.000,00 / \mathrm{kg}$ per tumpukan (dalam bahasa lokal) karena produksinya yang masih terjangkau. Apabila dibandingkan dengan akses harga pangan beras mahal yaitu dengan harga $\mathrm{Rp}$ $13.000,00 / \mathrm{kg}$ sampai Rp.15.000,00/kg. Responden rumah tangga mengatakan untuk bisa mendapakan pangan beras yang terjangkau perlu menumpuh waktu kurang dari 20 menit ke pasar distrik atau 2 jam ke pasar Kabupaten Kota, bahkan sebagian besar responden juga mengatakan sebelum adanya perkembangan konsumsi baras untuk pembagian raskin hanya dibagikan 3 bulan sekali. Faktor inilah yang mengakibatkan perubahan keterjangkauan harga bisa berpengaruh positif maupun negatif terhadap komoditi lain. Responden rumah tangga cenderung berpendapat adanya perbedaan keterjangkauan harga pangan beras yang lebih murah dibandingkan harga pangan ubi dan sagu yang mahal. Hasil ini sesuai dengan penelitian Siregar (2002) dan Ilham et al. (2006) yang menyatakan bahwa guncangan harga pangan mempengaruhi inflansi sehingga kemudian akan berdampak negatif terhadap daya beli masyarakat.

\subsection{Konsumsi Pangan Ubi, Sagu, dan Beras Kg/Tahun Sebelum dan Setelah Perkembangan Konsumi Pangan Beras}

\section{Tabel 4.}

\begin{tabular}{|c|c|c|c|c|}
\hline \multicolumn{5}{|c|}{ Konsumsi Pangan $\mathrm{Kg}$ / Tahun } \\
\hline No & Komoditi & $\begin{array}{c}\text { Jumlah } \\
\text { Responden }\end{array}$ & $\begin{array}{l}\text { Jumlah } \\
\text { Keluarga }\end{array}$ & $\begin{array}{l}\text { Jumlah } \\
\mathrm{kg} / \mathrm{thn}\end{array}$ \\
\hline 1. & $\begin{array}{c}\text { Sebelum } \\
\text { perkembangan } \\
\text { konsumsi beras } \\
\text { (tahun 2012) }\end{array}$ & & & \\
\hline & -Ubi & $28(70 \%)$ & 140 orang & $788,15 \mathrm{~kg} / \mathrm{thn}$ \\
\hline & -Sagu & $40(100 \%)$ & 199 orang & $1.298 \mathrm{~kg} / \mathrm{thn}$ \\
\hline & -Beras & $40(100 \%)$ & 199 orang & $957,3 \mathrm{~kg} / \mathrm{thn}$ \\
\hline 2. & $\begin{array}{c}\text { Setelah } \\
\text { perkembangan } \\
\text { konsumsi beras } \\
\text { (tahun 2016) }\end{array}$ & & & \\
\hline & -Ubi & $12(30 \%)$ & 59 orang & $182,4 \mathrm{~kg} / \mathrm{thn}$ \\
\hline & -Sagu & $40(100 \%)$ & 199 orang & $728 \mathrm{~kg} / \mathrm{thn}$ \\
\hline & -Beras & $40(100 \%)$ & 199 orang & $1.443,8 \mathrm{~kg} / \mathrm{thn}$ \\
\hline
\end{tabular}

Sumber: Data Primer diolah, 2017.

Tabel 4 dapat dilihat bahwa konsumsi pangan lokal ubi setelah perkembangan konsumsi pangan beras hanya 30\% rumah tangga yang mengkonsumsi pangan lokal ubi sebesar $182,4 \mathrm{~kg} / \mathrm{thn}$. Perubahan ini sesuai dengan hasil penelitian terhadap konsumsi ubi pada rumah tangga di Kampung Makimi yang menunjukan rata-rata mengkonsumsi 
ubi kurang dari $1 \mathrm{~kg} / \mathrm{hari}$. Hasil tabel penelitian juga menunjukan sebelum perkembangan konsumsi pangan beras terlihat bahwa dari total 40 responden rumah tangga, hanya $70 \%$ rumah tangga yang mengkonsumsi pangan lokal ubi.

Tabel tersebut juga menunjukkan konsumsi pangan lokal sagu sebelum dan setelah adanya perkembangan konsumsi beras, masih terdapat $100 \%$ rumah tangga memilih mengkonsumsi pangan sagu, namun hasil penelitan menunjukan jumlah tahunnya berbeda. Rata-rata konsumsi sagu kurang dari $1 \mathrm{~kg} / \mathrm{hari}$, rumah tangga juga tidak mengkonsumsi pangan sagu setiap hari, akibatnya konsumsi pangan sagu rumah tangga di Kampung Makimi semakin berkurang sehingga konsumsi sagu hanya 728 $\mathrm{kg} /$ tahun. Perubahan perkembangan konsumsi beras setelah perkembangan konsumsi beras terdapat $100 \%$ rumah tangga yang mengkonsumsi pangan beras sebesar $1.443,8$ $\mathrm{kg} / \mathrm{thn}$.

Berdasarkan hasil penelitian konsumsi pangan beras setelah adanya perkembangan konsumsi pangan beras, rata-rata rumah tangga mengkonsumsi beras hampir setiap hari atau sebanyak $2 \mathrm{~kg}$ sampai $3 \mathrm{~kg}$ per/hari. Responden rumah tangga mengatakan perubahan pola konsumsi menjadi pangan beras karena mudah di dapat, mudah diolah rasanya enak lebih mengenyangkan, akibatnya berdampak pada konsumsi kg pangan lokal ubi dan sagu yang semakin berkurang. Hasil penelitian menunjukan adanya dampak perubahan konsumsi kg pangan beras rumah tangga terhadap konsumsi komoditi ubi dan sagu, sebagai pangan pokok di Kampung Makimi.

\subsection{Dampak Perubahan Pola Konsumsi Pangan Ubi, Sagu, dan Beras Sebelum dan Setelah Perkembangan Konsumsi Beras}

Sejak Orde Baru, beras menjadi komoditas strategis secara politis, sehingga peranan pemerintah terhadap perkembangan produksi dan konsumsi beras sangat intensif. Pemerintah telah menetapkan berbagai kebijakan yang berkaitan dengan perberasan, mulai dari industri hulu hingga hilir. Kebijakan tersebut dilakukan secara terus menerus termasuk diantaranya kebijakan beras untuk orang miskin yang dikenal dengan raskin yang di perlakukan untuk semua provinsi.

Dampak dari kebijakan yang bias akan beras adalah terjadinya pergeseran pola konsumsi pangan lokal masyarakat, terutama di daerah-daerah yang makanan pokoknya bukan beras seperti di Kampung Makimi. Berdasarkan hasil penelitian diketahui bahwa masyarakat di Kampung Makimi, Distrik Makimi, Kabupaten Nabire telah beralih dari mengkonsumsi pangan lokal menjadi pangan beras. Lebih jelasnya dampak perubahan pola konsumsi pangan lokal ubi dan sagu menjadi konsumsi beras dapat dilihat pada tabel 5. 
Tabel 5.

Dampak Perubahan Pola Konsumsi Pangan Ubi, Sagu dan Beras di Kampung Makimi, Distrik Makimi, Kabupaten Nabire

\begin{tabular}{llcc}
\hline \multirow{2}{*}{ Komoditi } & Kategori & $\begin{array}{c}\text { Pebelum Konsumsi Pangan } \\
\text { perkembangan } \\
\text { konsumsi beras } \\
\text { (tahun 2012) }\end{array}$ & $\begin{array}{c}\text { Setelah } \\
\text { perkembangan } \\
\text { konsumsi beras } \\
\text { (tahun 2016) }\end{array}$ \\
\hline \multirow{3}{*}{ Ubi } & Sedikit & - & $87,5 \%$ \\
& Cukup & - & $12,5 \%$ \\
\hline \multirow{3}{*}{ Sagu } & Banyak & $100 \%$ & - \\
\hline & Total & $100 \%$ & $100 \%$ \\
\hline \multirow{3}{*}{ Beras } & Sedikit & - & $72,5 \%$ \\
& Cukup & - & $10 \%$ \\
\hline & Banyak & $100 \%$ & $100 \%$ \\
\hline & Total & $100 \%$ & $10 \%$ \\
\hline
\end{tabular}

Sumber:Data Primer diolah,2017.

Keterangan:(Sedikit< 0,3 kg/org/hari), (Cukup 0,3 kg/org/hari), (Banyak > 0,3 $\mathrm{kg} / \mathrm{org} / \mathrm{hari})$.

Tabel 5 dapat dilihat bahwa perubahan konsumsi pangan pokok lokal ubi dan sagu mengalami penurunan sedangkan konsumsi beras meningkat. Kondisi ini seolah-olah menggambarkan bahwa sumber karbohidrat hanya bersumber dari beras, sehingga pola konsumsi pangan yang terlalu bergantung pada satu jenis pangan dapat menimbulkan kekurangan dalam jenis pangan rumah tangga. Pola konsumsi pangan yang mengutamakan satu jenis pangan tidak dapat menjamin keseimbangan gizi yang memadai, akibatnya gaya hidup dan pola konsumsi pangan rumah tangga cenderung tidak sehat yang menyebabkan meningkatnya jumlah penderita penyakit Diabetes Meliatus. Berdasarkan data kesehatan Distrik Makimi, Kampung Makimi menunjukan jumlah penderita penyakit Diabetes Meliatus di Distrik Makimi tahun 2013-2016, mengalami peningkatan penyakit Diabetes Meliatus dengan jenis kelamin laki-laki dan perempuan, sebanyak 240 orang, sedangkan penderita penyakit Diabetes Meliatus di Kampung Makimi ditemukan rata-rata yang terjangkit adalah laki-laki sebanyak 45 orang. Jumlah penderita Diabetes Meliatus di Kampung Makimi adalah 18,75\% dari Distrik Makimi.

\section{Kesimpulan dan Saran}

\subsection{Kesimpulan}

Berdasarkan hasil pembahasan di atas dapat disimpulkan bahwa dampak perubahan pola konsumsi pangan lokal ubi dan sagu menjadi pangan beras di Kampung Makimi adalah terjadi pergeseran konsumsi masyarakat secara masif. Perubahan pola konsumsi pangan lokal ubi dan sagu menjadi pangan beras di Kampung Makimi, mengakibatkan tingkat kesukaan konsumsi pangan lokal ubi dan sagu menurun. 
Sebagian besar rumah tangga lebih menyukai mengkonsumsi pangan beras, karena rasanya yang enak dan mudah dijangkau. Dapat dilihat dengan besarnya jumlah konsumsi beras sebanyak 1.443,8 kg/tahun, sedangkan jumlah konsumsi ubi sebanyak $182,4 \mathrm{~kg} / \mathrm{tahun}$ dan sagu sebanyak $728 \mathrm{~kg} / \mathrm{tahun}$. Dampak negatif dari kebijakan dan program pemerintah untuk ketersediaan pangan beras mengakibatkan berkurangnya produksi pangan lokal ubi dan sagu. Ketersediaan konsumsi pangan lokal ubi dan sagu pun berkurang, sehingga harga ubi dan sagu menjadi mahal. Perubahan pola konsumsi pangan lokal ubi dan sagu menjadi beras mengakibatkan terjadinya peningkatan penyakit Diabetes Meliatus di Kampung Makimi sebanyak 18,75\% dari Distrik Makimi.

\subsection{Saran}

Berdasarkan hasil kesimpulan diatas maka saran yang dapat disampaikan sebagai masukan adalah perlu upaya pengolahan pangan lokal menjadi komoditi yang bernilai tambah yang dapat menarik rumah tangga untuk mengkonsumsi pangan lokal. Pemerintah diharapkan menyusun aturan terkait program kedaulatan pangan khususnya pangan lokal ubi dan sagu. Kebijakan pemerintah untuk bantuan raskin sebaiknya di kurangi kuotanya, dan di gantikan dengan program subsidi pangan yang berbasis pangan lokal. Perlu adanya punyuluhan mengenai penganekaragaman konsumsi pangan yang bergizi dan seimbang terutama dalam memanfaatkan potensi pangan lokal.

\section{Ucapan Terimakasih}

Terima kasih kepada Kepala Kampung Makimi Bapak Lamberth Woromboni, beserta Kepala Keluarga rumah tangga yang telah meluangkan waktu untuk penulis melaksanakan penelitian, hingga termuat di e-jurnal.

\section{Daftar Pustaka}

Abidin. M. 2015. Dampak Kebijakan Impor Beras dan Ketahanan Pangan Dalam Perspektif Kesejahteraan Sosial (Artikel Study Kepustakaan).

Ayhuwan,N,J.2010. Analisis Tingkat Konsumsi Beras dan Pangan Lokal di Desa Latuhalat Kecamatan Nusaniwe Kota Ambon. Skripsi. Fakultas Pertanian Universitas Pattimura.

BPS. 2015. Produksi Komoditi Pangan di Provinsi Papua. BKP .2015 .Produksi Pangan Lokal di Provinsi Papua. Badan Ketahanan Pangan Provinsi Papua. Badan Pusat Statistik Provinsi Papua.

BPS. Tahun 2013-2016. Kerjasama BAPPEDA. Badan Pusat Statistik Kabupaten Nabire.

Ellen DF. SN Lubis. ginting. 2013. Analisis Konsumsi Pangan Beras dan Pangan Non Beras.(:Desa Bagan Serdang Kecamatan Pantai Labu Kabupaten Deli Serdang

Gabriel JM. 2013. Perubahan Pola Konsumsi Pangan Rumah Tangga dari Mengonsumsi Pangan Lokal ke Pangan Beras pada Kecamatan Letimur Selatan Kota Ambon. Jurnal AGRILAN Vo ll.

Https:// wordpress.com/2008/04/28/ Konsumsi-pangan-lokal-di-Papua rendah.

Juliet V. R Felecia. P. Adam. M Turukay. 2013. Tingkat Ketergantungan Masyrakat Terhadap Konsumsi Beras di Kecamatan Nusaniwe Kota Ambon, Jurnal Agrilan. Agribisnis Fakultas Pertanian, Universitas Pattimura.

Nur S. 2014. Dampak Kebijakan Raskin terhadap Pola Konsumsi Pangan Lokal di Papua. Tesis. Sekolah Pasca Sarjana Institut Pertanian Bogor.

Susenas Panel. (2008-2010). Provinsi Papua 